\title{
Breve percurso histórico da Hermenêutica Bíblica
}

\author{
Pedro Paulo Alves dos Santos
}

\section{Introdução}

\begin{abstract}
Para permanecer simbólico, é necessário que o bíblico de texto permaneça em diálogo dinâmico e vital com o evento originário da autocomunicação divina, ou seja, com a revelação transmitida pela tradição viva da Igreja. Nesta recolocação, o conceito de inspiração pode ser assumido como o ponto de partida para redesenhar o equilíbrio necessário e o intercâmbio fecundo, que deve haver entre o 'sensus fidei', trabalho exegético, sistematização teológica e discernimento do magistério ${ }^{1}$.
\end{abstract}

A Hermenêutica Bíblica ${ }^{2}$ reside tanto na história do pensamento judai$\mathrm{co}^{3}$, como naquele cristão.

\footnotetext{
${ }^{1}$ BORGONOVO, Per rimanere simbolico, è necessario che il testo bíblico rimanga in dialogo dinamico e vitale con l'evento originario dell'autocomunicazione divina, ovvero con la rivelazione trasmessa dalla tradizone vivente della Chiesa. In questa ricollocazione, il concetto di ispirazione può essere assunto come il punto di partenza per redisegnare il necessario equilibrio e l'interscambio fecondo che deve esserci tra 'sensus fidei', lavoro esegetico, sistematizzazione teologica e discernimento del magistero, 1999, p. 63.

${ }^{2}$ GRECH, P., Il Messaggio Bíblico e la sua Interpretazione. Saggi di Ermeneutica, teologia ed esegesi, EDB, Bologna, 2005, esp. Ermeneutica Biblica: Breve Prospetto Storico, 9-22, Ermeneutica Biblica nel XX secolo, 189-202; HARRISVILLE, R. A. \& SUNDBERG, W., The Bible in the Modern Culture. Theology and Historical-Critical Method. Michigan: Grand Rapids, 1995; TARDIEU, M., Les Règles de l'Interprétation. Paris, Cerf, 1987; CAQUOT
} 
Em geral, a palavra hermenêutica está associada a antigas formas de superar, atualizar, controlar a interpretação dos textos "canônicos", i.é., aqueles escolhidos pela Comunidade, como sagrados e portadores de mensagem religiosa normativa.

$\mathrm{Na}$ sua conduta, parece pertencer à chamada teologia fundamental ${ }^{4}$, ramo da teologia que se ocupa dos Princípios e Fundamentos da Revelação e da Fé em relação às ciências, à Filosofia da Religião $0^{5}$ à cultura.

Na perspectiva da exegese bíblica, pode significar simplesmente o método para fazer exegese, isto é, para chegar à intenção original de um escritor bíblico, ou melhor, para extrair do texto bíblico pensamentos úteis para a vida cristã.

Do período do Iluminismo em diante, com suas questões específicas de leitura ${ }^{6}$, a hermenêutica implica também a relação entre ciência e fé na interpretação bíblica ${ }^{7}$.

Da Reforma, no século XVI, a concepção de Hermenêutica passa a ser uma ciência autônoma que se ocupa desde os problemas como a arte da compreensão, o valor e a interpretação da tradição humanista, o conhecimento como Hermenêutica do ser, a historicidade da verdade, o papel do sujeito na interpretação, até as várias funções da linguagem e das relações entre as filosofias e ideologias.

Neste campo, compreende-se a amplidão acarretada por todas estas tarefas, ocupando-se de problemas gnosiológicos, ontológicos, históricos e lingüísticos que invadem o inteiro campo da Teologia fundamental.

A Hermenêutica Bíblica antiga, tanto Judaica ${ }^{8}$ como cristã ${ }^{9}$, nos dará ocasião de rastrear os problemas e características principais.

A., et alii. Naissance de la Méthode critique. Colloque du Centenaire de l'École biblique et Archeologique française de Jerusalém, Paris, Cerf, 1992.

3 FISHBANE, M., The Exegetical Imagination. On Jewish Thought and Theology, Cambridge, 1998.

${ }^{4}$ LACOSTE, J.-Yves, Hermenêutica, In: LACOSTE, J.-Yves (ed.), Dicionário Crítico da Teologia, São Paulo, Loyola/Paulinas, 2004, p. 816-822.

${ }^{5}$ GREISH, Jean, Le Buisson Ardent et les Lumières de la Raison, T. III. Vers une paradigme herméneutique, Paris, Cerf, 2004.

${ }^{6}$ GRAFTON, Anthony. L' Umanista come Lettore, In: CAVALLO, G. e CHARTIER, R. Storia della Lettura nelo Mondo Occidentale, $3^{\text {a }}$ ed., Bari-Napoli, Laterza, 2004, p. 199-243.

${ }^{7}$ Neste período prepara-se a chegada do Método Histórico-Crítico, que a partir da Reforma Protestante, mas, sobretudo no século XVIII vai se impor na metodologia da exegese Bíblica cristã e ocidental. LAPLANCHE, F., La Marche de la Critique Biblique d'Érasme à Spinoza, In: CAQUOT A., et alii. Naissance de la Méthode critique. Colloque du Centenaire de l'École biblique et Archeologique française de Jerusalém, Paris, Cerf, 1992.

${ }^{8}$ ALON, G., Jews, Judaism and the Classical World. Hebrew University Press, Jerusalem, 1977. Sobre a história da leitura nesta cultura, BONFIL, R. La Lettura nelle Comunità 
Os dois princípios Hermenêuticos judaicos permanecem, no entanto a haggadá e a halakká. Por haggadá entende-se a narrativa da História de Israel na Páscoa, i.e, quando os hebreus, atravessando o Mar dos Juncos, na Península do Egito, "retornam" ao País de Canaã, à "terra prometida".

Deste núcleo narrativo se constroem as identidades narrativas da consciência de Israel.

Diversos gêneros literários produzidos na história da literatura judaica, como por exemplo, os midrashin (darash = exegese) são leituras interpretativas de natureza alegorizante de fatos e narrações de Israel.

Os Targumin, produzidos em língua aramaica, são textos homiléticos, que, pouco a pouco, foram assumindo um lugar na hermenêutica da liturgia, explicando os textos do Torah (Lei Mosaica) e dos profetas. Podem ser também, reconhecidos no famoso estilo "parabólico", utilizado por Jesus em sua pregação ${ }^{10}$.

Quanto à Halakká, esta consiste no corpo jurídico-literário de Israel. São as coleções de textos e tradições da Lei Mosaica, dos Códigos de comportamento.

Textos da interpretação de corpos jurídicos, provavelmente oriundos do período do reinado de Davi e Salomão. Pois, nesse momento, no $\mathrm{X}^{0}$ século, estabeleciam-se, por escrito, e foram organizados, em códigos, as leis, em parte de origem Mosaica.

Além de leis oriundas das reformas ocorridas no período do quarto século a.C. depois do retorno da Babilônia.

\section{A Hermenêutica Bíblica Judaica}

A criação da exegese judaica ${ }^{11}$ ocorreu no período anterior à Revolta Macabéia. Grande número de "correções" (tiqunê soperin) foi obra de escri-

Ebraiche dell'Europa Occidentale in Età Medievale, In: CAVALLO, G. e CHARTIER, R., Storia della Lettura nel Mondo Occidentale, $3^{\mathrm{a}}$ ed., Bari-Napoli, Laterza, 2004, p. 155-197.

9 DANIELOU, J., Théologie du Judéo-Christianisme, $2^{\mathrm{a}}$ ed., Paris, Desclée/Cerf, 1991; , Message Évangelique et Culture Hellenistique, $2^{\text {a }}$ ed., Paris, Desclée/Cerf, 1991; , Le Origines du Christianisme Latin, $2^{\text {a }}$ ed., Paris, Desclée/Cerf, 1991.

${ }^{10}$ CASCIARO, 2001, p. 323-344

${ }^{11}$ TREBOLLE, J.B., A Bíblia Judaica e a Bíblia cristã. Introdução à História da Bíblia, Vozes, Petrópolis, 1996, p. 511-592; LONGENECKER, R. N., Biblical Exegesis in the Apostolic Period, $2^{\text {a }}$ ed., Michigan, Eerdmans, 1999, esp., p. 6-36; SMEND, R., Israelitische und Jüdische Geschichte. Zur Entstehung von Julius Wellhausen Buch, In: SCHÄFER, Geschichte-Tradition-Reflexion, Band I. Tübingen, J.C.B. Mohr, 1996, p. 35-42. 
bas saduceus da época hasmonéia, de modo que os fariseus herdaram um texto já corrigido.

Para falar de gênesis e desenvolvimento da interpretação bíblica das épocas persa e helenística, diversos são os fatores a serem considerados:

1. Escritos tardios, ou "deutero-canônicos": como as coleções da literatura sapiencial e apocalíptica constituíssem necessariamente uma interpretação e reflexão sobre os livros e tradições de época anterior, também os "apócrifos", livros sem valor para a coleção sagrada (cânon), prosseguiram no esforço de atualização e reescritura dos textos bíblicos;

2. Muitos textos bíblicos já ofereciam dificuldades de intelecção, além de verdadeiras corrupções textuais, exigindo todo um esforço de interpretação;

3. Momentos de ameaça de desintegração sócio-religiosa, como o exílio da Babilônia fez necessária a criação de "releitura" e uma nova compreensão de velhos textos legais e tradições históricas;

4. A necessidade de traduzir textos sagrados dos hebraicos para a língua aramaica, e para língua grega, obrigava a um grande esforço de interpretação e de atualização dos textos hebraicos ${ }^{12}$.

Para muitos autores, a Escritura é a primeira intérprete de si mesma. Um fenômeno de intertextualidade ${ }^{13}$, na verdade, no tocante à formação de textos antigos, como aqueles do AT, no qual não cabe estabelecer um corte radical entre a forma final de um texto e os comentários posteriores.

Desde os começos da tradição bíblica, a interpretação é parte integrante do seu texto ${ }^{14}$.

Os profetas clássicos do $\mathrm{VIII}^{\circ}$ século inspiraram-se em tradições antigas, para interpretar os acontecimentos de sua época. Seus discípulos não fizeram outra coisa que continuar este processo interpretativo, criando e recriando o texto.

O processo da interpretação continuará, inclusive, depois da estabilização do texto ${ }^{15}$.

\footnotetext{
${ }^{12}$ Sobre a Literatura dos Targuns: LE DÉAUT, R., Introduction à la Littérature Targumique, Roma, PIB, 1988.

${ }^{13}$ TEUGELS, G., Did Moses see the Chariot? The Link between Exod 19-20 and Ez 1 in Early Jewish Interpretation, In: VERVENNE, M., Studies in Book of Exodus. Redaction Reception - Interpretation, Louvain, BETHEL76 (1996), p. 595-603.

${ }^{14}$ Segundo TREBOLLE, A Bíblia Judaica e a Bíblia cristã, p.514, "Embora muito rudimentar, os livros do AT já conhecem os procedimentos de interpretação que mais tarde utilizou a exegese rabinica, tanto do tipo "peshat", que trata de fundamentar na Escritura as normais legais não contempladas na Torá".
} 
O Judaísmo está (totalmente) conformado pela interpretação da Escritura. É o judaísmo do período farisaico que estabelece uma ponte entre a Torá revelada e a interpretação da mesma transmitida na Tradição, projetando, no Sinai, o início desta relação.

Deste modo, a interpretação revela novos significados, alcançados, não por revelação direta, mas através do trabalho exegético ${ }^{16}$.

$\mathrm{Na}$ história da interpretação judaica, um dado importante é a tradição histórica, na qual o elemento Hermenêutico reside na convicção de que a tradição é regra de exegese de textos sagrados.

Isto é, o contexto da recepção de textos torna-se critério Hermenêutico para entender e reescrever outros textos. Isto porque, para eles, a revelação (fonte de autoridade e a função do texto escrito) não era nem imediata, nem direta.

Esta se produz sempre em contacto com a tradição autorizada que a transmite e interpreta ${ }^{17}$.

No caso das relações entre os textos e exegese, pode-se distinguir, a partir de pontos de vista diversos: a Escritura (= textos bíblicos) é à base da exegese, que, por princípio, é derivada, ou pelo contrário, a Escritura é ela mesma um texto interpretado e a quinta-essência de toda a tradição interpretativa $^{18}$.

Nesta perspectiva, A Bíblia é o precipitado último de um longo processo exegético ${ }^{19}$.

O texto bíblico nasceu imerso numa corrente de tradições orais e este foi sempre acompanhado por um corpo de comentários orais, a Mishna rabi$n i c a^{20}$ (a tradição oral por excelência do Judaísmo), pois a tradição oral nun-

\footnotetext{
${ }^{15}$ Este processo percorre e explica também a formação do "corpus litterarius" na esfera do Novo Testamento, em particular no âmbito da tradição paulina, REDALIÉ, Yann, Paul après Paul, Génève, Labor et Fides, 1994.

${ }^{16}$ LUST, J. e VERVENNE, M., Deuteronomy and Deuteronomic Literature, Louvain, BETHEL 83 (1997).

${ }^{17}$ WAL, A., Van der, Themes from Exodus in Jeremiah 30-31, In VERVENNE, M., Studies in Book of Exodus. Redaction - Reception - Interpretation, BETHEL76 (1996), Louvain, p. $559-566$.

${ }^{18}$ Nesta linha de pensamento "midráshico" (darash = interpretação exegética) sobre a Escritura bíblica Judaica, FISHBANE, M., Midrash and Nature of Scripture, In:

The Exegetical Imagination. On Jewish Thought and Theology, Cambridge, 1998. É clássico neste campo o texto do mesmo autor: rael, Oxford, 1985.

${ }^{19}$ TREBOLLE, 1996, p. 515.

${ }^{20}$ WEINGREEN, J., From Bible to Mishna. The Continuity of Tradition, Oxford, 1959.
} 
ca deixou de influir na interpretação do texto bíblico e, inclusive, na sua própria conformação.

\section{A Tradução dos LXX ou Septuaginta}

A versão da $\mathrm{LXX}^{21}$, obra de tradução é, ao mesmo tempo, e por isso mesmo, uma obra de interpretação. A versão da LXX constitui-se numa obra da exegese judaica.

Porém, para entender as perspectivas da leitura cristã são obrigatórias, ao menos, duas vertentes culturais:

- De um lado, o Helenismo ${ }^{22}$, cultura que se desenvolve sob a inspiração de Alexandre Magno e, mesmo durante o período romano, continuará a influenciar as posturas assumidas pelas primeiras gerações cristãs.

- Do outro, a obra de "tradução" dos LXX, a Bíblia Grega dos Judeus de Alexandria, entregue à Biblioteca de Ptolomeu IV, no século $\mathrm{III}^{\mathrm{O}}$, e que, segundo os autores, será o texto de referência da formação dos escritos e da hermenêutica dos Escritos do cristianismo primitivo ${ }^{23}$.

Neste texto, de fato, percebe-se a formação de uma interpretação produzida na Diáspora judaico-helenista, e que influencia a escrita literária, o léxico e as categorias de origem filosófica dos escritos do Novo Testamento.

Além da língua grega, que será a escolhida para a fixação dos textos e idéias do Cristianismo, em suas incursões no Helenismo do $\mathrm{I}^{\mathrm{O}}$ século, na Província Oriental do Império Romano ${ }^{24}$.

\footnotetext{
${ }^{21}$ HARL, M., Gênesis, In: La Bible d"Alexandrie, Vol. 1, Paris, Cerf, 1986, p. 7: "Au III siècle avant notre ère, á Alexandrie, la Bible hebraïque fût traduite en grec: plus exactement, les cinq livres qui forment ce que nous appelons le Pentateuque, la Loi juive, La Torah. A Jusqu'a former, aux alentours de l'ère chrétienne, l'ensemble des livres grecs que nous que nous appelons la Bible des Spetantes, ou plus simplement, la "Septante»".

${ }^{22}$ PREAUX, Cl., Le Monde Hellénistique. La Grèce et L'Orient 323-146 av.J.-C, Paris, PUF, 1978.

${ }^{23}$ HARL, M., et alii. La Bible D"Alexandrie, Paris, Cerf, 1986; HARL, M et DORIVAL, G., et MUNNICH, O., La Bible Grecque des Septante: Du Judaïsme Hellénistique au Christianisme Ancien, Paris, Cerf, 1988; HARL, M., La Langue de Japhet. Quinze Etudes sur la Septante et le Grec des Chrétiens, Paris, Cerf, 1992; DORIVAL, G. et MUNNICH (org.). Selon les Septante. Hommage à Marguerite Harl, Paris, Cerf, 1995.

${ }^{24}$ Uma visão geral, entre Cristianismo e Helenismo: TOYNBEE A., A Vitória do Cristianismo. In: Helenismo. História de uma Civilização. $4^{\mathrm{a}}$ ed., Rio de Janeiro, Zahar, 1975, p. 204213; JELLICOE, S., The Septuaginta and Modern Study. $3^{\text {a }}$ ed., Indiana, Eisenbrauns, 1993; NOCK, A. D., Cristianisme et Hellénisme, In: Lectio Divina 77 (1973), Paris, Cerf; G. VERMES, G., La Literature Juive intertestamentaire a la Lumière d"un siècle de recherches et decouvertes, In: KUNTZMANN R. e SCHLOSSER, J. (org.), Études sur le Judaïsme Hellénistique. In Lectio Divina 119 (1983), Paris, Cerf, p. 19-40 e SCHWARTZ, J., La com-
} 
Existiriam conexões entre a obra e o contexto da $L X X$, como testemunho de uma das formas do Judaísmo antigo, o da Diáspora helênica e a hermenêutica da formação do Cânon do NT?

Caso se pudesse demonstrar, de que maneira tais conexões possibilitam uma melhor configuração do Cristianismo Primitivo?

Tratava-se da única fonte, até as descobertas de Qumran, da tradução da "Bíblia" hebraica, fixada posteriormente $\left(\mathrm{I}^{\circ}-\mathrm{II}^{\mathrm{O}}\right.$ séc. d.C.) e das idéias do Judaísmo alexandrino e palestinense ${ }^{25}$.

Constata-se, cada vez mais, o uso deste texto na era cristã, não somente pelos autores da Tradição posterior à flutuação do Cânon neotestamentário, mas, sobretudo, pelos próprios hagiógrafos ${ }^{26}$.

Isto é, o contexto da Formação do Cânon Cristão, que implica a decisão pela formação de um cânon propriamente judaico, aquele do "Antigo Testamento",27.

Além disso, a questão pertinente é a pergunta de HARL: Como a LXX, obra Judaica, tornou-se o "A.T." da Jovem Igreja cristã? $?^{28}$

\section{A Hermenêutica Moderna}

Os personagens e idéias das principais correntes do pensamento Hermenêutico que dominaram o panorama dos séculos $\mathrm{XVII}^{29}$ em diante, a começar com a postura de Martinho Lutero ${ }^{30}$ até H. G. Gadamer, serão revisi-

munauté d"Edfou (Haute-Égypte) jusqu a fin de Règne de Trajan. Réflexions sur les Juifs dans plat-pays Égyptien, In: Lectio Divina 119 (1983), Paris, Cerf, p. 61-70.

${ }_{25}$ TREBOLLE, $A$ Versão Grega da Septuaginta. p. 353.

${ }^{26}$ TREBOLLE, A Versão Grega da Septuaginta, p. 354; DORIVAL, G., L'Histoire de la Septante dans le Judaïsme antique, In: HARL, M. et DORIVAL, G. et MUNNICH, La Bible Grecque des Septante, p. 31-127, esp., p. 31-38.

${ }^{27}$ PENNA, R., 'Rapporto tra l'Antico e Nuovo Testamento. Nouvi Approcci', In: Biblica 81 (2001), Roma, p. 95-104; FANULLI, Antonio. Memoria tra teologia ed ermeneutica, In: FRANCO, Ettore (org.), Mysterium Regni. Mysterium Verbi, Bologna, EDB, 2001, p. 239245.

${ }^{28}$ HARL, 1992, p. 269.

${ }^{29}$ RICOEUR, P., Il compito dell 'ermeneutica partendo da Schleiermacher e da Dilthey, In: , Dal Testo all"Azione, Milano, Jaca Book, 1986, p. 71-97.

${ }_{30}$ REVENTLOW, H. G., Essere giustificati per fede: Martin Lutero, In:

Storia dell'Interpretazione Bíblica.Rinascimento, Riforma, Umanesimo. Monferrato (AL), Piemme, 1999, p. 91-120; GILMONT, Jean-Francois, Riforma Protestante e Lettura, In: CAVAllo, G. e CHARTIER, R., Storia della Lettura nelo Mondo Occidentale, $3^{\mathrm{a}}$ ed., Roma-Bari, Laterza, 2004, p. 243-276; THISELTON, Anthony, The Hermeneutics of Inquiry: From the Reformation to Modern Theory, In: , New Horizons in Hermeneutics. Michigan, Zondervan, 1992, p. 179-204, esp., p. 186-189; GRECH, P., Ermeneutica Biblica: 
tados, em seus pontos de vistas mais interessantes, devido à influência que exerceram sobre o desenvolvimento contemporâneo da Hermenêutica, seja em campo bíblico ${ }^{31}$, como naquele Teológico, aplicado às questões sobre Deus (a Antiga Teodicéia) seja mesmo aplicado à Religião (Filosofia da Religião) $)^{32}$.

Com Lutero e a Reforma Protestante, inicia-se um novo ciclo na história da Hermenêutica Bíblica. O próprio contexto da criação da imprensa ${ }^{33}$, que deveria recriar as condições de leitores no século XVI é, para alguns autores, um dos elementos que contribuiu para esta reviravolta da leitura interpretativa da Bíblia na Europa moderna, com interessantes seguimentos contemporâneos para a exegese.

Com seus princípios da sola Scriptura e Scriptura sui ipsius interpres, a hermenêutica luterana marca o início de uma reviravolta que pode ser definida como uma passagem da autoridade (Igreja) para a razão (sujeito), que, de fato, passará pelo crivo das relações conflituosas da Igreja com o "modernismo", no século XIX.

Importa, para a perspectiva da hermenêutica bíblica ocidental, a desvinculação deste método em relação à Igreja de Roma e, sobretudo, com a Tradição dos Padres ( $\mathrm{II}^{\circ}$ ao VIII ${ }^{\circ}$ séc. d.C).

Assim, mesmo com a pressuposição que um leitor munido do Espírito Santo é capaz, individualmente, de resolver suas questões hermenêuticas com as Escrituras, a leitura da Bíblia, entre os protestantes, apesar da divinização das Escrituras, como argumento para justificar esta tomada de distância em relação às 'auctoritas' da Tradição, segue a tendência do Humanismo do Renascimento, ao igualar-se com os critérios de leitura do ambiente de textos clássicos.

Para a Hermenêutica, segue-se que, daquele momento em diante, esta passa de método para interpretar a Sagrada Escritura, para o status de uma disciplina independente, tendo como objeto obras literárias ou artísticas ${ }^{34}$.

Breve prospetto storico, In: , Il Messaggio Biblico e la sua Interpretazione. Bologna, EDB, 2005, p. 9-21.

${ }^{31}$ GRECH, P., L'Ermeneutica Biblica nel Secolo XX, In: Biblico e la sua Interpretazione, Bologna, EDB, 2005, p. 189-202.

${ }^{32}$ GREISH, Jean, Le Buisson Ardent et les Lumières de la Raison. L'Invention de la Philosophie de la Religion. Vers un Paradigme herméneutique, Paris, Cerf, 2004.

${ }_{33}$ BURKE, P., Uma História Social do Conhecimento de Gutenberg a Diderot, Rio de Janeiro, J. Zahar, 2003; MAN, John, A Revolução de Gutenberg, Rio de Janeiro, Ediouro, 2002.

${ }^{34}$ GEFFRÉ, Claude, De L"Herméneutique des textes à l'herméneutique biblique, In: CAQUOT A., et alii. Naissance de la Méthode critique. Colloque du Centenaire de l'École biblique et Archeologique française de Jerusalém, Paris, Cerf, 1992, p. 279-286. 
Ele vive em pleno romantismo alemão, imbuído do espírito protestante e iluminista ${ }^{35}$. Suas teorias são da intuição genial que une o leitor e o escritor e resolve o problema da distância que separa um do outro.

Em primeiro lugar, a hermenêutica é arte da compreensão, não da explicação ou objeto da retórica. Não se limita às obras escritas na Antiguidade, mas a toda espécie de discurso, mesmo oral.

$\mathrm{O}$ ato de falar (ou escrever) é um fato lingüístico que se deve considerar, seja no plano histórico de desenvolvimento da língua, seja naquele da fala.

O estilo é a alma de tudo. Existe, pois, um aspecto estrutural e outro fenomenológico.

Assim como falar e escrever é um "ato" que, quase sempre, prescinde do $e u$, o círculo de compreensão não se fecha nunca, porque a genialidade do intérprete encontra, no texto, verdades não entendidas a partir do autor, que, no ato de compreensão, tornam-se um novo evento histórico e, desta maneira, qualquer outra circunstância de leitura. A subjetividade do intérprete está contida no círculo Hermenêutico ${ }^{36}$.

35 THISELTON, Anthony, Schleiermacher's Hermeneutics of Understanding, In: , New Horizons in Hermeneutics, Michigan, Zondervan, 1992, p. 204-237. Sobre algumas questões do "iluminismo" que se referem aos problemas epistemológicos, LABIO, Catherine, Origins and the Enlightenment. Aesthetic Epistemology from Descartes to Kant, London, Cornell, 2004.

${ }^{36}$ Nesta mesma perspectiva da subjetivação do intérprete, como mediador, por excelência, W. Von Humboldt, no campo da historiografia insiste na afirmação que é o pesquisador (historiador) a dar uma unidade lógica aos fragmentos que resultam dos documentos. Ele, o historiógrafo, fornece uma unidade lógica, análoga àquela de seu próprio momento histórico. Já, para J.G. Droysen, compreender um autor do passado não significa somente explicá-lo, mas compreendê-lo melhor do que ele a si mesmo, pois sobre uma época anterior, se conhece mais os seus condicionamento, ignorados por ele, mas não a nós. Sobre este amplo espectro de problemas da historiografia moderna: KOSELLECK, Reinhart. Futuro Passado. Contribuição à semântica dos tempos históricos, Rio de Janeiro,: Contraponto/Puc-Rio, 2006; CASTORIADIS, Cornelius, Sujeito e Verdade no mundo histórico-social, Rio de Janeiro, Civilização Brasileira, 2007; ARÓSTEGUI, Julio, A pesquisa Histórica. Teoria e Método, Bauru, Edusc, 2006. Uma reflexão mais filosófica sobre as relações entre tempo, sujeito e evento histórico: RICOEUR, Paul, Evénement et Sens, In: CASTELLI, Enrico (org.), Rivelazione e Storia. Roma, Instituto di Studi Filosofici, 1971, p. 15-34. Sobre os estudos historiográficos no campo bíblico: ASSOCIAZIONE BIBLICA ITALIANA. La Storiografia Nella Bibbia, Bologna, EDB, 1986. 
O terceiro grande canteiro grande se abre com o projeto diltheniano de uma "crítica da Razão histórica" que ambiciona jogar em relação às ciências do espírito que se constituem em suas autonomias epistemológicas nas primeiras décadas do século de XIX, um papel comparável ao que jogou a Crítica da pura Razão de Kant em relação à física newtoniana ${ }^{37}$.

No quadro do "espírito objetivo" hegeliano, ele distingue a ciências entre Naturwissenschaft (ciências da natureza) e Geisteswissenschaft (ciências humanísticas) $)^{38}$.

Enquanto para Schleiermacher, a compreensão é um fato lingüístico; para Dilthey, torna-se um fato vital. A experiência da vida de todos os homens, seus sentimentos, sua compreensão do próprio mundo social e cultural são externados por meio de expressões vitais (Lebensäusserungen).

Objeto próprio da Hermenêutica são aquelas manifestações que exprimem o entendimento do homem a propósito de seu mundo vital.

No processo histórico, tais expressões vitais se cristalizam em exteriorizações que perderam o contato com a fonte da experiência, é, portanto, incapazes em seu papel, de re-converter estas expressões humanísticas para experiência vital do homem contemporâneo.

A compreensão se torna um princípio existencial, sem deixar de ser um conceito metodológico das ciências humanísticas. Porém, cada vez mais, esta distinção, entre compreensão e interpretação, torna-se uma categorização criticável ${ }^{39}$.

\footnotetext{
${ }^{37}$, GREISCH, Le troisième grand chantier s'ouvre avec le project diltheyen d"une «critique de la Raison historique», qui ambitionne de jouer, par rapport aux sciences de l'esprit qui se constituent dans leur autonomie épistemologique dans le prémières décennies du XIX ${ }^{\mathrm{e}}$ siècle, un rôle comparable à celui que jouait la Critique de la Raison pure de Kant par rapport à la physique newtonienne, 2004, p. 25.

${ }^{38}$ GREISH, Jean, Le Manteau de la Providence et le fureur de l"histoire: La critique de la raison hisotirque et l"herméneutique de l"expérience religieuse (W. Dilthey), In: , Le Buisson Ardent et les Lumières de la Raison, p. 110-134; HARRISVILLE, R. A. \& SUNDBERG, W., The Bible in the Modern Culture. Theology and HistoricalCritical Method, Michgan, Grand Rapids, 1995.

39 Paul Ricoeur critica este antagonismo em sua teoria hermenêutica, como uma forma de solução nas relações entre as ciências humanas e as naturais, para a problemática epistemológica da hermenêutica, aliás, como fundação da sua autonomia científica, Il Compito dell"ermeneutica partendo da Schleiermacher e da Dilthey, In: , Dal Texto all'Azione, Milano, Jaca Book, 1989, p. 71-97.
} 
Apoiado sob a égide de Husser ${ }^{41}$ e Dilthey, Martin Heidegger conduz a Hermenêutica ao seu auge existencial ${ }^{42}$.

O Filósofo de Marburg quis estudar o ser como tal, aquilo que impede os seres de caírem no nada. O Dasein é o ser que se manifesta na existência, pois, como em Dilthey, o homem não é uma essência pré-constituída e absoluta, mas é a sua mesma possibilidade e ganha a sua existência com as suas escolhas.

Neste sentido, a filosofia é essencialmente uma hermenêutica, e a ontologia é a interpretação do ser. Assim, a compreensão humana é lingüística por natureza (a casa do homem), a linguagem ordena a compreensão. E, as assertivas autênticas dos pensadores ou poetas ${ }^{43}$ são, na verdade, segundo Heidegger, interpretações da existência.

Por isso, o estudo filosófico-literário (humanístico) é considerado como estudo da história da auto-compreensão do Dasein e de suas possibilidades.

Este aspecto lingüístico é desenvolvido no segundo Heidegger: a verdade é a-lêtheia, um desvelar-se do ser-do-homem, que se torna, por meio de sua compreensão e de sua linguagem, um auto-falante da voz muda do Ser.

O hermeneuta, portanto, não é alguém que explica somente o significado das palavras, pois, estas servem somente para revelar uma linguagem de época.

${ }^{40}$ Considerada a melhor biografia do Filósofo: SADRANSKI, Rüdiger, Heidegger,. Um Mestre da Alemanha entre o bem e o mal, São Paulo, Geração Editorial, 2000.

${ }^{41}$ LAVIGNE, Jean-François, Husserl et la Naissance de la Phénoménologie (1900-1913), Paris, Épiméthée-PUF, 2005.

${ }^{42}$ GREISH, Jean, Quel Dieu peut encore nous sauver? Le Tornant ontologique de l'Herméneutique et ses Conséquences, In: Le Buisson Ardent et les Lumières de la Raison, p. 498-734. Sobre as questões propriamente de hermenêutica filosófica; RORTY, Richard, Ensaios sobre Heidegger e Outros, Rio de Janeiro, Relume\&Dumará, 1999, na perspectiva da história da Filosofia; ROVIGHI, Sofia Vanni, História da Filosofia Contemporânea, $2^{\mathrm{a}}$ ed., São Paulo, Loyola, 2001, esp., p. 397-404.

${ }^{43}$ HEIDEGGER, M., Hölderlin and Essence of Poetry, In? RICHTER, D.H., The Critical Tradition. Classic Texts and Contemporary Trends, $2^{\mathrm{a}}$ ed., Boston/New York, Bedford/St.Martin`s, 1998, p. 563-571. 
Uma linguagem, talvez, muito estreita para explicar a totalidade da compreensão e, portanto, traduzível em uma linguagem hodierna, mais apta à nossa auto-compreensão.

\section{4. H.-G. Gadamer (1900-2002) ${ }^{44}$}

De acordo com Gadamer, a hermenêutica não conquista sua dimensão filosófica na medida em que ela não se satisfaz com a função de reagrupar e comparar diferentes regras e métodos de interpretação, mas porque está interessada no fenômeno da compreensão como tal, e nas suas condições de possibilidade ${ }^{45}$.

A insistência sobre a linguagem do segundo Heidegger conduz ao estudo de H.-G. Gadamer, Wahrheit und Methode $(1960)^{46}$.

Hermenêutica é compreensão, mas esta compreensão ocorre quando o leitor, vivendo no presente e, portanto, herdeiro de certos pré-conceitos que lhe chegaram, através da contínua história cultural, confronta-se com o texto.

Os horizontes do texto e do leitor se fundem um ao outro, de modo que aquilo que era pré-compreensão se modifica e torna-se compreensão. Mas esta compreensão não é absoluta, ela é também um elo histórico na cadeia de várias compreensões históricas do passado.

${ }^{44}$ SHULZ, W. Ammerkungen zur Hermeneutik Gadamers. In BUBNER, R. \& CRAMER, K.,M \& WIEHL, R., Hermeneutik und Dialetik. Tomo I. Tübingen: J.C.B. Mohr, 1970, p. 305-316. Sobre o Método Hermenêutico de H.-G. Gadamer, um resumo "didático" útil para uma breve introdução: A Interpretação da Bíblia na Igreja. São Paulo: Paulinas, 1994, p.8889. Um aprofundamento, LENGESFELD, G., A Presença Permanente da Revelação na Escritura e na Tradição. In: Mysterium salutis, I/2, Petrópolis, Vozes, 1972, p. 7-27; THISELTON, The Hermeneutics of metacriticism and Foundation of Knowledge. In:

New Horizons in Hermeneutics. Michigan, Zondervan, 1992, p. 313-330.

${ }^{45}$ GREISCH, D'après Gadamer, l'Herméneutique ne conquiert sa dimension philosophique que si elle se contente pas de reagruper et de comparer les différentes règles et méthodes de l'interprétation, mais qu'elle s'intéresse au phénomène du comprender comme tel, et à ses conditions de possibilité, 2004, p. 135.

${ }^{46}$ GADAMER, H-G., The Elevation of the Historically of Understanding of the Status of Hermeneutical Principle, In: RICHTER, D.H., The Critical Tradition. Classic Texts and Contemporary Trends, p. 671-690; GREISH, Jean, La Source et le Gouffre: Memoire Culturelle et Traditions Religieuses (H.-G. Gadamer), In , Le Buisson Ardent et les Lumières de la Raison, p. 134-159. Mais especificamente sobre a Hermenêutica bíblica: THISELTON, A., Gadamer's Claim for "the Universality of Hermeneutical Problem" and the Development of Critiques of Language and Knowledge, In: , New Horizons in Hermeneutics. Zondervan, Michigan, 1992, p. 322-330. 
O continuum da tradição é Wirkungsgeschichte (=história do efeito) dos textos, na origem da nossa cultura, e se manifesta na linguagem, na qual os valores culturais estão enraizados. Por mais que o texto seja normativo, a interpretação é um processo contínuo e não se pode dizer que uma interpretação seja definitiva. Para Gadamer, tradição é a cadeia das explicações que concretizam a compreensão.

Para ele, o autor perde a importância de frente ao texto que agora adquire a paternidade do leitor.

De certa maneira, a Hermenêutica bíblica irá, por meio de seu percurso moderno, reconhecer-se nos diversos pontos destes personagens e suas construções teóricas.

Estas tendências vão concentrar-se na figura de um discípulo de Lutero, da mesma Reforma que, no século XVI, irá modificar a maneira de ler e interpretar as Escrituras e de produzir textos exegéticos e de hermenêutica bíblica ${ }^{47}$.

\subsection{Rudolf Bultmann (1884-1976)}

O gênio teológico de Bultmann está longe de limitar-se à erudição pura, estabelece a questão da significação dos textos antigos para o mundo de hoje, e abre a questão das modalidades de sua interpretação ${ }^{48}$.

Além de sua importante contribuição exegética, Bultmann é recordado pela sua contribuição hermenêutica ${ }^{49}$.

A Formsgeschichte (história da formas) aplicada aos Evangelhos Sinóticos sublinha o profundo ceticismo de Bultmann pela historicidade dos evangelhos, isto porque ele depositava somente na Fé (sola Fidei) a crença e o conhecimento possíveis de Jesus Cristo.

${ }^{47}$ PETRUCCI, A., Libri, editori e pubblico nell"Europa moderna,. $2^{\mathrm{a}}$ ed., Roma/Bari, Laterza, 2003.

${ }^{48}$ COLLANGE, 2004, p.324.

49 COLLANGE, Jean-François, BULTMANN Rudolf 1884-1976, In: LACOSTE, J.-Yves (ed.)., Dicionário Crítico da Teologia, São Paulo, Loyola/Paulinas, 2004, p. 324-326; THISELTON, Anthony, The Hermeneutics of the Earlier Heidegger and Bultmann's Approach to Paul, In: , New Horizonss in Hermeneutics, p. 279-283; GRECH, P., Il Messaggio Bíblico e la sua Interpretazione. Saggi di Ermeneutica, teologia ed esegesi, Bologna, EDB, 2005, esp., Ermeneutica Biblica: Breve Prospetto Storico, p. 9-22, Ermeneutica Biblica nel XX secolo, esp., p. 194-196; HARRISVILLE, R. A. \& SUNDBERG, W., The Bible in the Modern Culture. Theology and Historical-Critical Method, Michigan, Grand Rapids, 1995. 
Neste sentido, ele é um autêntico herdeiro do Luteranismo. Outra contribuição é a sua teoria da "demitização" dos textos bíblicos como hermenêutica autêntica para Fé, ao utilizar e interpretar os Evangelhos ${ }^{50}$.

De tradição racionalista, Bultmann entende que a linguagem sobrenatural não pode ser aceita pelo homem moderno, para tal é necessário que esta linguagem seja traduzida em categorias aceitáveis ao homem moderno.

Trata-se de traduzir o mito de maneira filosófica. Esta concepção ele herda de Heidegger, aquele de Sein und Zeit (Ser e Tempo).

Bultmann não deseja reduzir a Teologia à Filosofia, ele quer somente indicar um paralelismo entre o núcleo de pensamento cristão e aquele de Heidegger.

A finalidade da hermenêutica não é uma leitura "objetivante" do texto, mas, seguindo Dilthey e Heidegger, um diálogo com o autor para chegar a uma auto-compreensão existencial de frente a Deus.

O teólogo de Marburg entende que não se pode falar de Deus objetivando-O, mas somente dentro da relação com Deus, que se constitui então no ser-para-mim. Não existe, por isso, 'Heilsgeschichte', uma história da salvação.

Os grandes conceitos do Cristianismo são, por isso, mitológicos, pois o que vale é o evento da Fé. Bultmann admite somente como sobrenatural o ato de crer quando este está em contato com a palavra.

Todo resto é "demitizável"

\section{Conclusão}

"Aproveitando os progressos realizados em nossa época pelos estudos lingüísticos e literários, a exegese bíblica utiliza cada vez mais métodos novos na análise literária (...)". Recentemente entre as inumeráveis experimentações, uma Comunicação entre exegetas africanos e europeus, confirma, de certa maneira, esta irrenunciável tarefa interdisciplinar do teólogo e do exegeta.

Passamos, em revista as questões levantadas pela consciência recente da Igreja, acerca da interpretação exegética, na expectativa de oferecer aos teóricos da hermenêutica aplicada a textos teológicos um suporte históricointerpretativo.

\footnotetext{
${ }^{50}$ MCKNIGHT, E., Der hermeneutische Gewinn der neuen literatischen Zugänge in der neutestamentlichen Bibelinterpretation, In: BZ(NF), 47 (1997), Münster, Heft 2, p. 161-173, esp., p. 164-166.

${ }^{51}$ MALEVEZ, L., Le Message Chrétien et Le Mythe. La Théologie de Rudolf Bultmann, Paris, Brouwer, 1954.
} 
Isto é, quais são os pontos de discussão, na posição do Magistério e dos exegetas, em relação à exegese de textos bíblicos, que coincidem com abordagens hermenêuticas de processos de leitura:

Baseado na abordagem das "leituras" produzidas pela hermenêutica bíblica, em confronto com teorias literárias contemporâneas percorremos uma breve história, a partir do problema da intenção do texto e do autor, e já localizados, numa recente teoria do texto, como "comunicação literária".

Essa pode ser uma "pequena" forma de história da hermenêutica bíblica entre aquelas de dimensões bíblicas e de natureza mais filosóficoteológica.

Outra abordagem mais diretamente bíblica e contemporânea suporia a apresentação de um estrato da vasta e complexa obra de Paul Ricoeur ${ }^{52}$ e de Luigi Pareyson ${ }^{53}$, no tocante às tentativas 'modernas' de acomodar os princípios teológicos e às razões das ciências hermenêuticas. Tarefa essa que ficará para outra ocasião.

\begin{abstract}
Biblical Hermeneutical lives so much in the history of the Jewish thought, as that Christian. In general, the word hermeneutics is associated to old forms of overcoming, to update, to control the interpretation of the "canonical" texts, those chosen by the Community, as sacred and bearers of normative religious message. In her conduct, it seems to belong to the call fundamental theology; branch of the theology is in charge of the Beginnings and Foundations of the Revelation and of the Faith in relation to the sciences, to the Philosophy of the Religion, to the culture.

In the perspective of the biblical exegesis, it can simply mean the method to do exegesis, that is, to arrive to a Biblical writer or better original
\end{abstract}

\footnotetext{
${ }^{52}$ Qu'est-ce q" "un Texte? Expliquer et Comprendre, In: BUBNER \& CRAMER \& WIEHL, Hermeneutik und Dialetik. T. II., Tübingen; J.C.B. Mohr, 1970, 181-200. O mesmo autor acaba de ser lançado no Brasil, no exercício interdisciplinar delicado e exigente entre os saberes, com a tradução de uma obra de co-autoria sobre a Exegese e a Hermenêutica; LACOQUE, André et RICOEUR, Paul. Pensando Biblicamente, Bauru, Edusc, 2001. O problema é tão agudo, a ponto de exigir um posicionamento claro da Pontifícia Comissão Bíblica, $A$ Interpretação da Bíblia na Igreja, São Paulo, Paulinas, 1994, p. 46; OKURE, T., I will open my mouth in parables (Matt 13:35): An Case for a Gospel-Based Biblical Hermeneutic, In: NTS 46 (2000), p. 89-111. Assim como a recente coletânea em homenagem ao Cardeal Martini; ANGELINI, G. (org.), La Rivelazione Attestata. La Bibbia fra Testo e Teologia, Milano, Glossa, 1998.

${ }^{53}$ PAREYSON, L., Originarietà dell'Interpretazione, In: BUBNER, R. \& K.Cramer \& R. Wiehl, Hermeneutik und Dialetik, T. I, Tübingen, J.C.B. Mohr, Tübingen, 1970, 353-372.
} 
intention, to extract of the text biblical useful thoughts for the Christian life. Of the period of Enlightenment in before, with their specific subjects of reading, the hermeneutics also implicates the relationship between science and faith in the biblical interpretation.

\section{Pedro Paulo Alves dos Santos}

Doutor em Letras pela Pontifícia Universidade Católica do Rio de Janeiro Doutor em Teologia Bíblica pela Pontificia Università Gregoriana Di Roma

\section{Referências Bibliográficas}

BORGONOVO, Giantonio, Uma proposta di rilettura dell'ispirazione biblica doppo gli apporti della Form e Redaktionsgeschichte. In: GRECH, Prosper et Alii (org.), Interpretazione della Bibbia nella Chiesa. Vaticano: Edittrice Vaticana, 1999, p. 41-63.

CAQUOT A. et alii, Naissance de la Méthode critique. Colloque du Centenaire de l'École biblique et Archeologique française de Jérusalem, Paris, Cerf, 1992.

CASCIARO, José Maria, Para una Hermenêutica de las parábolas evangélicas. In: FRANCO Ettore (org.), Mysterium Regni. Mysterium Verbi, Bologna, EDB, 2001, p. 323-344.

COLLANGE, Jean-François, BULTMANN Rudolf 1884-1976. In: LACOSTE, J.-Yves (ed.), Dicionário Crítico da Teologia, São Paulo, Loyola/Paulinas, 2004, p. 324-326.

GRECH, P., Il Messaggio Bíblico e la sua Interpretazione. Saggi di Ermeneutica, teologia ed esegesi, Bologna, EDB, 2005.

GREISH, Jean, Le Buisson Ardent et les Lumières de la Raison. L"Invention de la Philosophie de la Religion. Vers un Paradigme herméneutique, Paris, Cerf, 2004.

HARL, M. et alii,. La Bible D"Alexandrie, Paris, Cerf, 1986.

HARL, M et DORIVAL, G., et MUNNICH, O. La Bible Grecque des Septante: Du Judaïsme Hellénistique au Christianisme Ancien, Paris, Cerf, 1988.

LACOSTE, J.-Yves, Hermenêutica. In: LACOSTE, J.-Yves (ed.), Dicionário Crítico da Teologia, São Paulo, Loyola/Paulinas, 2004, p. 816-822.

MCKNIGHT, E., Der hermeneutische Gewinn der neuen literatischen Zugänge in der neutestamentlichen Bibelinterpretation. In: BZ(NF), 47 (1997), Münster, Heft 2, p. 161-173, esp., p. 164-166. 
REVENTLOW, H. G., Storia dell"Interpretazione Bíblica. Rinascimento, Riforma, Umanesimo. Monferrato (AL), Piemme, 1999, p. 91-120.

RICOUER, Paul, Compito dell"ermeneutica partendo da Schleiermacher e da Dilthey. In: , Dal Texto all'Azione, Milano, Jaca Book, 1989, p. 71-97.

, Evénement et Sens. In: CASTELLI, Enrico (org.). Rivelazione e Storia, Roma, Instituto di Studi Filosofici, 1971, p. 1534.

SHULZ, W., Ammerkungen zur Hermeneutik Gadamers. In BUBNER, R. \& CRAMER, K.,M \& WIEHL, R., Hermeneutik und Dialetik, Tomo I, Tübingen, J.C.B. Mohr, 1970, p. 305-316.

THISELTON, Anthony, New Horizons in Hermeneutics, Michigan: Zondervan, 1992.

TREBOLLE, J.B., A Bíblia Judaica e a Bíblia cristã. Introdução à História da Bíblia, Petrópolis, Vozes, 1996. 